\title{
Epidemiology, Clinical and Paraclinical Presentations of Pulmonary Embolism: A Cross-Sectional Study in a Sub-Saharan Africa Setting
} \author{
Nina Chebou' ${ }^{2}$, Anastase Dzudie ${ }^{1,3}$, Serge Arnold Ebongue ${ }^{4}$, Bruno Tengang , \\ Henry Luma Namme ${ }^{1,3}$ \\ ${ }^{1}$ Douala General Hospital, Douala, Cameroon \\ ${ }^{2}$ Faculty of Medicine and Pharmaceutical Sciences, University of Douala, Douala, Cameroon \\ ${ }^{3}$ Faculty of Medicine and Biomedical Sciences, University of Yaounde 1, Yaounde, Cameroon \\ ${ }^{4}$ Military Hospital, Douala, Cameroon \\ ${ }^{5}$ Centre des Maladies Respiratoires, Douala, Cameroon \\ Email: *mbatchou.ngahane@yahoo.com
}

Bertrand Hugo Mbatchou Ngahane 1,2*, Félicité Kamdem 1 ,2, Silvain Raoul Simeni Njonnou3, Fernando Kemta Lekpa1, Yacouba Mapoure Njankouo1,2, Sidick Mouliom1, Henri Roger Ngote1,

How to cite this paper: Mbatchou Ngahane, B.H., Kamdem, F., Njonnou, S.R.S., Chebou, N., Dzudie, A., Ebongue, S.A., Tengang, B., Lekpa, F.K., Njankouo, Y.M., Mouliom, S., Ngote, H.R. and Namme, H.L. (2019) Epidemiology, Clinical and Paraclinical Presentations of Pulmonary Embolism: A Cross-Sectional Study in a Sub-Saharan Africa Setting. Open Journal of Respiratory Diseases, 9, 89-99. https://doi.org/10.4236/ojrd.2019.93008

Received: April 26, 2019

Accepted: July 26, 2019

Published: July 29, 2019

Copyright $\odot 2019$ by author(s) and Scientific Research Publishing Inc. This work is licensed under the Creative Commons Attribution International License (CC BY 4.0).

http://creativecommons.org/licenses/by/4.0/ (c) (i) Open Access

\begin{abstract}
Background: Venous thromboembolic (VTE) disease burden is increasing worldwide, representing a major cause of cardiovascular death and public health problem. Pulmonary embolism (PE) is the most serious clinical presentation of VTE. Epidemiological and clinical data on PE are still lacking in Africa, particularly in Cameroon. This study aimed at determining the clinical features as well as imaging presentation and outcome of pulmonary embolism. Methods: A cross-sectional study was carried out in three hospitals in Douala. We retrospectively reviewed patient records admitted for PE from January 2009 to May 2017. We collected data on epidemiology, clinical presentation, venous Doppler/pulmonary computed tomographic angiography (CTA), and outcome. Results: We included 103 patients (56 males) with PE. Their median age was 52 years. The main risk factors were obesity (49.5\%), hypertension (35.0\%), long trip (24.3\%) and cancer (18.4\%). The most frequent clinical presentations were dyspnoea $(83.4 \%)$, chest pain $(78.6 \%)$, and cough (40.8\%). Additionally, pleural effusion (32.8\%), atelectasis (25.7\%) and pulmonary hyperlucency (20.0\%) were the most frequent findings on chest $\mathrm{X}$-ray. The main abnormalities found in electrocardiogram were sinus tachycardia (63.4\%), S1Q3T3 aspect (37.6\%) and right axial deviation (28.7\%). Moreover, right cavities dilatation (26.0\%), pulmonary artery hypertension
\end{abstract}


(35.0\%) and pulmonary artery dilatation $(21.0 \%)$ were the main echocardiographic findings. Low-molecular-weight heparin (LMWH) was the initial anticoagulant in all cases. There were 19 (18.4\%) in-hospital deaths, and the mean hospital stay was $8.5 \pm 5$ days. Conclusion: PE is not rare in our setting. Obesity, long trip and cancer are the main risk factors, while dyspnoea, chest pain and respiratory distress are the main clinical presentation for $\mathrm{PE}$. LMWH remains the therapeutic agent of choice. Lastly, in-hospital mortality is very high.

\section{Keywords}

Epidemiology, Africa, Venous Thromboembolism, Symptoms

\section{Introduction}

Venous thromboembolic (VTE) disease is a public health problem worldwide. Pulmonary embolism (PE), which is the most serious presentation of VTE, is the third most common cause of death from cardiovascular disease after heart attack and stroke [1] [2]. It is still undiagnosed, due to the lack of suspicion and availability of appropriate diagnostic testing such as multi-detector computed tomographic angiography (CTA), especially in low resource setting [3] [4] [5]. Moreover, it has a 30 -day mortality rate between $9 \%$ and $11 \%$ [2]. Incidence of PE is growing worldwide, particularly in high income countries [6] [7] [8] [9]. The clinical presentation of pulmonary embolism is non-specific. Symptoms may vary from mild chest pain to shock due to right ventricular failure in patients with massive PE. However, patients with PE sometimes present without any symptoms, the diagnosis being coincidently when investigating for other conditions [10]. Major risk factors for PE include recent surgery or trauma, lower limb fractures and joint replacements, and spinal cord injury, immobilization, malignancy. However $30 \%$ of patients with PE have no detectable provoking factors [11]

In Sub-Saharan Africa, preliminary studies have shown that PE was scarce [5] [12] [13] [14] [15]. Recent studies on the continent have reported more cases, but the limited resources, especially the access to CTA, still contribute to the reduced number of PE cases reported [16] [17] [18] [19] [20]. Despite this situation, the increase in the prevalence of risk factors of VTE suggests that pulmonary embolism will be more frequent in Sub-Saharan Africa. The present study aimed at determining the clinical features as well as imaging presentation and outcome of pulmonary embolism.

\section{Methods}

\subsection{Study Design and Setting}

This is a descriptive study which was carried out in the intensive care unit and medical services of three hospitals in Douala. Douala is a city of 3 million inha- 
bitants and the economic capital of Cameroon. The three hospitals were selected for the study: 1) Douala General Hospital (DGH), a tertiary care level and teaching hospital; 2) Douala Military Hospital (DMH), a second level hospital; and 3) the Centre des Maladies Respiratoires (CMR), a private clinic in charge of patients who present respiratory problems. These three medical centres easily have access to chest X-ray and computed tomographic angiography, as well as to intensive care unit.

\subsection{Study Participants}

Patients admitted for a pulmonary embolism between January 2009 and May 2017 were included in the study. Patients aged less than 18 years were excluded as well as patients whose medical records were lacking data on the finding of thoracic CTA. Ethics approval was obtained from the ethical Review Board of the University of Douala.

\subsection{Data Collection}

Patients were identified using the registers of the services. The medical files were retrieved from the archives and the following data were extracted: sociodemographic factors (age and sex), clinical presentation (chest pain, dyspnoea, haemoptysis, cough, syncope, pulse rate and blood pressure), comorbidities and risk factors of VTE, as well as the results of chest X-ray, electrocardiogram, echocardiography and CTA. The diagnosis of PE was defined by the identification of a thrombus in the pulmonary artery or any of its branches. The following risk factors were investigated: obesity (body mass index of $30 \mathrm{~kg} / \mathrm{m}^{2}$ ), cancer, previous VTE, HIV infection, pulmonary tuberculosis, myocardiopathy, vascular trauma, chronic kidney disease, recent long trip (duration $>4$ hours within the last 4 weeks), pregnancy/early post-partum or post-abortum ( $<6$ weeks) and recent surgery $(<4$ weeks). Immobilisation was defined as bed rest for more than three consecutive days in preceding month, irrespective of the cause. Additionally, the medication used for the initial anticoagulant treatment and the hospitalisation outcome were recorded. The possible outcomes were death, discharge and complications (lung infection, bleeding and bed sores).

\subsection{Statistical Analysis}

Data were entered and analysed using IBM SPSS Statistics 20 software. Continuous variables were expressed as mean \pm standard deviation. Dichotomous variables were expressed as counts and percentages.

\section{Results}

During the study period, 130 patients were identified with a diagnosis of pulmonary embolism. Twenty-seven of them were excluded because of missing or incomplete medical records. Finally, a total of 103 cases of PE were included in the study. Among them, 56 (54.4\%) were males, and the median age was 52 years 
(interquartile range: 41 - 63). Participants aged 50 to 59 years were the most represented (26.2\%). Table 1 shows the baseline characteristics of the study population.

Obesity (49.5), hypertension (35.0\%) and cancer (18.4\%) were the most common underlying comorbidities. The risk factors of venous thromboembolism found in this study are shown in Table 2. Obesity (49.5\%), hypertension (35.0\%), recent long travel (24.3\%), cancer (18.4\%), immobilisation (16.5\%) and recent surgery (15.5\%) were the most common risk factors. Moreover, Table 3 shows that the most frequent symptom in patients with $\mathrm{PE}$ was dyspnoea (83.4\%). Eight patients (7.8\%) presented signs of cardiogenic shock, while syncope was seen in 6 patients $(5.8 \%)$. Signs of deep venous thrombosis were found in 27 patients $(24.3 \%)$.

At presentation, electrocardiography was performed for 101 patients. Among them, 16 patients $(15.5 \%)$ had a normal electrocardiogram. Sinus tachycardia (63.4\%) was the most common finding. The S1Q3T3 pattern was seen in 38 patients (37.6\%) and the right bundle branch block in 11 patients (10.9\%). Among the 68 patients whose oxygen saturation $\left(\mathrm{SpO}_{2}\right)$ was noted upon arrival at the hospital, 23.5\% (16 patients) had $\mathrm{SpO}_{2}$ less than $90 \%$. The median $\mathrm{SpO}_{2}$ was $96 \%$ (interquartile range: 91 - 98).

Table 1. General characteristics of study population $(\mathrm{N}=103)$.

\begin{tabular}{|c|c|}
\hline Variables & Frequency (\%) \\
\hline \multicolumn{2}{|l|}{ Gender } \\
\hline Male & $56(54.4)$ \\
\hline Female & $47(45.6)$ \\
\hline \multicolumn{2}{|l|}{ Age (years) } \\
\hline Median age $\left(\mathrm{IQR}^{\star}\right)$ & $52(41-63)$ \\
\hline$<30$ & $8(7.8)$ \\
\hline $30-39$ & $12(11.7)$ \\
\hline $40-49$ & $23(22.3)$ \\
\hline $50-59$ & $27(26.2)$ \\
\hline $60-69$ & $21(20.4)$ \\
\hline$\geq 70$ & $12(11.7)$ \\
\hline Admission service & $21(22.6)$ \\
\hline Internal Medicine & $83(80.6)$ \\
\hline Intensive care unit & $20(19.4)$ \\
\hline \multicolumn{2}{|l|}{ Origin } \\
\hline Home & $53(52.4)$ \\
\hline Referred from other hospitals & $41(39.9)$ \\
\hline Transfered from other wards & $9(8.7)$ \\
\hline
\end{tabular}

$\left.{ }^{*}\right)$ interquartile range. 
Table 2. Venous thromboembolism risk factors in the study population $(\mathrm{N}=103)$.

\begin{tabular}{|c|c|}
\hline Risks factors & Frequency (\%) \\
\hline \multicolumn{2}{|l|}{ Medical risk factors } \\
\hline Hypertension & $36(35)$ \\
\hline Cancer & $19(18.4)$ \\
\hline Past history of deep venous thrombosis & $15(14.6)$ \\
\hline Myocardiopathy & $10(9.7)$ \\
\hline Diabetes & $9(8.7)$ \\
\hline HIV infection & $8(7.8)$ \\
\hline Arrhythmia & $7(6.8)$ \\
\hline Chronic Kidney disease & $5(4.9)$ \\
\hline Autoimmune disease & $3(2.9)$ \\
\hline Recent infection & $3(2.9)$ \\
\hline Sickle cell disease & $2(1.9)$ \\
\hline Stroke & $1(1)$ \\
\hline Pulmonary tuberculosis & $1(1)$ \\
\hline Varicose veins & $1(1)$ \\
\hline \multicolumn{2}{|l|}{ Surgical and gynecological risk factors } \\
\hline Recent surgery & $16(15.5)$ \\
\hline Post partum & $2(1.9)$ \\
\hline Pregnancy & $1(1)$ \\
\hline Abortion & $1(1)$ \\
\hline \multicolumn{2}{|l|}{ Other risk factors } \\
\hline Obesity & $51(49.5)$ \\
\hline Long trip & $25(24.3)$ \\
\hline Smoking & $18(17.5)$ \\
\hline Immobility & $17(16.5)$ \\
\hline Hormone therapy replacement & $6(5.8)$ \\
\hline
\end{tabular}

Table 3. Clinical and para-clinical presentation of pulmonary embolism.

\begin{tabular}{cc}
\hline Variables & Frequency (\%) \\
\hline Signs and symptoms $(\mathbf{n}=103)$ & $86(83.4)$ \\
Dyspnea & $81(78.6 \%)$ \\
Chest pain & $42(40.8)$ \\
Cough & $11(10.7)$ \\
Hemoptysis & $24(23.3)$ \\
Right heart failure & $8(7.8)$ \\
Cardiogenic shock
\end{tabular}




\begin{tabular}{|c|c|}
\hline Continued & \\
\hline Syncope & $6(5.8)$ \\
\hline Signs of deep venous thrombosis & $27(24.3)$ \\
\hline Chest X-ray finding $(\mathrm{n}=70)$ & \\
\hline Pleural effusion & $23(32.8)$ \\
\hline Atelectasis & $18(25.7)$ \\
\hline Pulmonary hyperlucency & $14(20)$ \\
\hline Pulmonary artery enlargement & $12(17.1)$ \\
\hline ECG $(n=101)$ & \\
\hline Sinus Tachycardia & $64(63.4)$ \\
\hline S1Q3T3 pattern & $38(37.6)$ \\
\hline Right axis deviation & $29(28.7)$ \\
\hline $\mathrm{T}$-wave inversion in leads V1-V4 & $26(25.7)$ \\
\hline Right bundle branch block & $11(10.9)$ \\
\hline Cardiac echography $(n=100)$ & \\
\hline Right ventricle dilatation & $26(26)$ \\
\hline Elevated pulmonary systolic pressure & $35(35)$ \\
\hline Pulmonary artery enlargement & $21(21)$ \\
\hline Right ventricle hypokinesis & $13(13)$ \\
\hline Mobile right heart thrombi & $9(9)$ \\
\hline
\end{tabular}

Chest X-ray was available in 70 patients, and the main findings were pleural effusion (32.3\%) and atelectasis (25.7\%). Transthoracic echocardiography was performed in 101 patients. Right ventricle dilatation (26.0\%) and elevated pulmonary systolic pressure $(35.0 \%)$ were the most frequent echocardiographic findings. The pulmonary CTA showed a bilateral pulmonary embolism in 40 patients $(38.8 \%)$ and a proximal location of pulmonary embolism in 75 participants (72.8\%).

Anticoagulant therapy was commenced in all cases with Low-molecular-weight heparin (LMWH) and followed with vitamin $\mathrm{K}$ antagonists (VKA) in 92 (89.3\%) and a new oral anticoagulant (rivaroxaban) in 11 (10.7\%) cases. Complications were mostly represented by pulmonary infection in 31 (30.1\%) patients and cardiogenic shock in $14(13.6 \%)$. Median duration of the hospital stay was 7 days (interquartile range: 5 - 11), while the in-hospital mortality rate was $18.4 \%$.

\section{Discussion}

This study is part of the rare studies on pulmonary embolism in Sub-Saharan Africa. It presents the key findings with regard to clinical characteristics and outcome of patients with PE. We found that PE mostly affects a younger popula- 
tion, with a median age of 52 years. In the northwest region of Cameroon, Abah et al. found a mean age of 56 years among patients with a diagnosed venous thromboembolism [21]. Similar results were noted in previous studies in other Sub-Saharan African countries [12] [16] [22] and in Asia [23] [24]. On the contrary, PE population consists of middle age to elderly people in western countries [2] [25]. Knowing that the risk of pulmonary embolism increases with age, the higher prevalence in developed countries is probably due to the increase of the life expectancy in these countries [26] [27].

The main risk factors in this study were obesity, hypertension, recent long trip, cancer, immobilisation and recent surgery. These results were similar to those found in previous reports in Sub-Saharan Africa [12] [15] [17] [18], Europe and Asia [25] [26]. The main symptoms at presentation in this study were dyspnoea, followed by chest pain and cough. These findings are similar to those found in other African countries [12] [16] [22] and in other parts of the world [2] [28] [29]. Syncope was the reason of admission in 5.8\%. A similar result was noted by Bakebe et al. in Democratic Republic of Congo [16]. A systematic review on PE in Europe showed a variation of syncope frequency from 6\% to 39\% [28]. This heterogeneity is probably due to the fact that syncope is usually present in severe $\mathrm{PE}$, which had various frequencies in different reports. The proposed mechanisms of syncope in PE includes 1) reduction of cerebral blood flow due to the decrease in cardiac output, 2) the vasovagal reflex and 3) cardiac arrhythmia and conduction disturbances due to right ventricle overload [30].

Signs of deep venous thrombosis were noted in $24.3 \%$, which is also found in previous reports [10] [31]. On the chest X-ray, pleural effusion, atelectasis and pulmonary hyperlucency were the most common findings, as reported in the literature [12] [16] [28]. It is established that chest X-ray is not a sensitive and specific tool for the diagnosis of PE [32], which was normal in $24.3 \%$ in our study. Moreover, chest X-ray is a non-invasive diagnostic assessment that can be used for the differential diagnosis of pulmonary embolism. Unsurprisingly, sinus tachycardia was the most observed on electrocardiography.

Pulmonary CTA was the diagnostic tool for PE. Its advent has been a major progress in the diagnosis of pulmonary embolism, especially in developing countries where the ventilation/perfusion scan is not available. Pulmonary CTA is known to have a good sensitivity and specificity for proximal PE, but less sensitive for distal location [33]. We found a proximal location of PE in $72.8 \%$ of participants. Similar result was found by Calwin Davidsingh et al. in India [32].

The most frequent abnormality on electrocardiogram (ECG) was sinus tachycardia, as found also in previous reports [12] [25] [32]. Although ECG can be normal in PE, other findings in PE include SIQ3T3 pattern, ST and T wave changes in anterior leads, RBBB, axis changes, transition zone shift to the right, P-pulmonale and atrial arrhythmia in severe PE. Cardiac echography findings were similar to the reports by Houenassi et al. and Bakebe et al., where right cavities dilatation and pulmonary arterial hypertension were the most frequent 
anomalies $(13,16)$. On the other hand, paradoxical septum, right ventricular dysfunction and right ventricular hypokinesis were noted by other previous reports. This discrepancy is probably due to the fact that in the latter reports, the proportion of severe PE was more important [2] [12] [32].

The in-hospital mortality rate of patients diagnosed with pulmonary embolism varies, depending on the setting of the studies. The $18.4 \%$ mortality rate found in our study is consistent with data reported by Kingue et al. [15] and Houenassi et al. [13]. However, Bakebe et al. found a mortality rate of $7.0 \%$ in Kinshasa [16]. The difference in severity of PE and the relatively low sample sizes of studies in Sub-Saharan Africa could explain the variability of the mortality rate. A remarkably low mortality rate of $3.4 \%$ was noted in a large study conducted in emergency department setting in the United States of America [2]. This difference in mortality rate could be explained by the fact that the length of stay in emergency department is usually lower than in conventional medical ward.

Although the present study is among the first multicentre report on PE in Sub-Saharan Africa, some limitations could be noted. First, the retrospective design used could be a source of recall bias. Herein, data were extracted from the medical records, and the findings could be underestimated, depending on the documentation of the records by physicians. However, a standardised data collection sheet was used in this study. Second, the reduced sample size in our study, compared to other studies in western countries, could be another limitation.

\section{Conclusion}

Obesity, long trip and cancer are the main risk factors for PE in Cameroon. Symptoms and imaging are similar to those of previous reports. In our setting, in-hospital mortality remains very high. Further studies with larger sample size are thus needed for a detailed description in Sub-Saharan Africa with a focus on the outcome.

\section{Funding}

The present study received no external funding.

\section{Authors' Contribution}

Conception and Design: MNBH, KF; Data collection: CN; Data analysis and Interpretation: MNBH; Drafting of the manuscript: NSRS. Reviewing the manuscript: DA, ESA, TB, KLF, MNY, MS, NHR, LNH. All authors read and approved the final draft for publication.

\section{Acknowledgements}

We thank the International Multidisciplinary Programme to Adress Lung Health in Africa (IMPALA) for its support. 


\section{Conflicts of Interest}

The authors declare no conflicts of interest regarding the publication of this paper.

\section{References}

[1] Goldhaber, S.Z. and Bounameaux, H. (2012) Pulmonary Embolism and Deep Vein Thrombosis. The Lancet, 379, 1835-1846. https://doi.org/10.1016/S0140-6736(11)61904-1

[2] Pollack, C.V., Schreiber, D., Goldhaber, S.Z., Slattery, D., Fanikos, J., O’Neil, B.J., et al. (2011) Clinical Characteristics, Management, and Outcomes of Patients Diagnosed with Acute Pulmonary Embolism in the Emergency Department: Initial Report of EMPEROR (Multicenter Emergency Medicine Pulmonary Embolism in the Real World Registry). Journal of the American College of Cardiology, 57, 700-706. https://doi.org/10.1016/j.jacc.2010.05.071

[3] Goldhaber, S.Z., Hennekens, C.H., Evans, D.A., Newton, E.C. and Godleski, J.J. (1982) Factors Associated with Correct Antemortem Diagnosis of Major Pulmonary Embolism. The American Journal of Medicine, 73, 822-826. https://doi.org/10.1016/0002-9343(82)90764-1

[4] Tambe, J., Moifo, B., Fongang, E., Guegang, E. and Juimo, A.G. (2012) Acute Pulmonary Embolism in the Era of Multi-Detector CT: A Reality in Sub-Saharan Africa. BMC Medical Imaging, 12, 31. https://doi.org/10.1186/1471-2342-12-31

[5] Saleh, J.A. and Alasia, D.D. (2007) Acute Pulmonary Embolism: A Review. Nigerian Journal of Medicine, 6, 11-17. https://doi.org/10.4314/njm.v16i1.37274

[6] DeMonaco, N.A., Dang, Q., Kapoor, W.N. and Ragni, M.V. (2008) Pulmonary Embolism Incidence Is Increasing with Use of Spiral Computed Tomography. The American Journal of Medicine, 121, 611-617. https://doi.org/10.1016/j.amjmed.2008.02.035

[7] Minges, K.E., Bikdeli, B., Wang, Y., Kim, N., Curtis, J.P., Desai, M.M., et al. (2015) National Trends in Pulmonary Embolism Hospitalization Rates and Outcomes for Adults Aged $\geq 65$ Years in the United States (1999 to 2010). American Journal of Cardiology, 116, 1436-1442. https://doi.org/10.1016/j.amjcard.2015.07.068

[8] Bouée, S., Emery, C., Samson, A., Gourmelen, J., Bailly, C. and Cotté, F.-E. (2016) Incidence of Venous Thromboembolism in France: A Retrospective Analysis of a National Insurance Claims Database. Thrombosis Journal, 14, 2-9. https://doi.org/10.1186/s12959-016-0078-0

[9] Yang, Y., Liang, L., Zhai, Z., He, H., Xie, W., Peng, X., et al. (2011) Pulmonary Embolism Incidence and Fatality Trends in Chinese Hospitals from 1997 to 2008: A Multicenter Registration Study. PLoS ONE, 6, e26861. https://doi.org/10.1371/journal.pone.0026861

[10] Bajaj, N., Bozarth, A.L., Guillot, J., Kojokittah, J., Appalaneni, S.R., Cestero, C., et al. (2014) Clinical Features in Patients with Pulmonary Embolism at a Community Hospital: Analysis of 4 Years of Data. Journal of Thrombosis and Thrombolysis, 37, 287-292. https://doi.org/10.1007/s11239-013-0942-8

[11] European Society of Cardiology (ESC) (2014) 2014 ESC Guidelines on the Diagnosis and Management of Acute Pulmonary Embolism. Endorsed by the European Respiratory Society. European Heart Journal, 35, 3033-3080. https://doi.org/10.1093/eurheartj/ehu283

[12] Diall, I.B., Coulibaly, S., Minta, I., Ho, B., Diakite, M., Sidibe, N., et al. (2011) Caus- 
es, Signs and Outcome of 30 Patients with Pulmonary Embolus. Le Mali Médical, 26, 3-6.

[13] Houenassi, M., Sacca-Vehounkkpe, J. and Tchabi, Y. (2013) Evaluation de la prise en charge de l'embolie pulmonaire dans un pays à faible niveau socio-économique: Cas du Benin. Cardiologie Tropicale, 136, 1-8.

[14] Elegbeleye, O.O. and Femi-Pearse, D. (1975) Pulmonary Embolism in Africans. Tropical and Geographical Medicine, 27, 31-33.

[15] Kingue, S., Tagny-Zukam, D., Binam, F., Nouedoui, C., Teyang, A. and Muna, W.F. (2002) Venous Thromboembolism in Cameroon (Report of 18 Cases). Medecine Tropicale: Revue du Corps de Sante Colonial, 62, 47-50.

[16] Bakebe, A., Kashongwe, I., Mulenga, C., Tshiasuma, M., Kabengele, B., Bisuta, S.F., et al. (2017) Pulmonary Embolism: Epidemiological Data and Diagnosis in Kinshasa Hospitals. International Journal of Tuberculosis and Lung Disease, 21, 875-879. https://doi.org/10.5588/ijtld.16.0418

[17] Kamdem, F., Ngahane, B.H.M., Hamadou, B., Mongyui, A., Doualla, M.S., Jingi, A.M., et al. (2018) Epidemiology, Clinical Presentations and In-Hospital Mortality of Venous Thromboembolism at the Douala General Hospital: A Cross-Sectional Study in Cameroon, Sub-Saharan Africa. World Journal of Cardiovascular Diseases, 8, 123-132. https://doi.org/10.4236/wjcd.2018.82012

[18] Manuel, A., Aufico, A., Africano, R., Peralta, T., Salas, A., Silva, A., et al. (2017) Clinical Profile, Management and Outcomes of Patients with Pulmonary Embolism: A Retrospective Tertiary Centre Study in Angola. Cardiovascular Journal of Africa, 28, 356-361. https://doi.org/10.5830/CVJA-2017-017

[19] Nganou-Gnindjio, C.N., Njonnou, S.R.S., Hamadou, B., Jemea, B., Mbede, M., Jingi, A.M., et al. (2018) Characteristics of Venous Thrombo-Embolic Disease in People with and without HIV Infection in Yaounde: A Cross-Sectional Study. Health Sciences and Diseases, 19, 21-26.

[20] Pessinaba, S., Atti, Y.D.M., Baragou, S., Pio, M., Afassinou, Y., Kpélafia, M., et al. (2017) Pulmonary Embolism at the University Hospital Campus of Lome (Togo): A Retrospective Study about 51 Cases. Pan African Medical Journal, 27, 129. https://doi.org/10.11604/pamj.2017.27.129.6855

[21] Abah, J.P., Menanga, A., Ngahane, B.H.M., Minkande, J.Z., Akono, M.N. and Kingue, S. (2016) Pattern of Venous Thromboembolic Diseases in a Resources-Limited Setting in Cameroon. Pan African Medical Journal, 23, 236. https://doi.org/10.11604/pamj.2016.23.236.7034

[22] Ogeng'o, J.A., Obimbo, M.M., Olabu, B.O., Gatonga, P.M. and Ong'era, D. (2011) Pulmonary Thromboembolism in an East African Tertiary Referral Hospital. Journal of Thrombosis and Thrombolysis, 32, 386-391.

https://doi.org/10.1007/s11239-011-0607-4

[23] Husain, S.J., Zubairi, A.B.S., Fatima, K., Irfan, M., Atif, M. and Saeed, M.A. (2009) Clinical Characteristics, Management and Outcome of Major Pulmonary Embolism: An Experience from a Tertiary Care Center in Pakistan. Journal of Pakistan Medical Association, 59, 372-375.

[24] Algahtani, F.H., Bayoumi, N., Abdelgadir, A., Al-Nakshabandi, N., Al Aseri, Z., Al Ghamdi, M., et al. (2013) Clinical Characteristics and Risk Factors of Pulmonary Embolism: Data from a Saudi Tertiary-Care Center. Journal of Thrombosis and Haemostasis, 11, 388-390. https://doi.org/10.1111/jth.12083

[25] Casazza, F., Becattini, C., Bongarzoni, A., Cuccia, C., Roncon, L., Favretto, G., et al. (2012) Clinical Features and Short Term Outcomes of Patients with Acute Pulmo- 
nary Embolism. The Italian Pulmonary Embolism Registry (IPER). Thrombosis Research, 130, 847-852. https://doi.org/10.1016/j.thromres.2012.08.292

[26] Alikhan, R., Cohen, A.T., Combe, S., Samama, M.M., Desjardins, L., Eldor, A., et al. (2004) Risk Factors for Venous Thromboembolism in Hospitalized Patients with Acute Medical Illness: Analysis of the MEDENOX Study. Archives of Internal Medicine, 164, 963-968. https://doi.org/10.1001/archinte.164.9.963

[27] Anderson, F.A., Wheeler, H.B., Goldberg, R.J., Hosmer, D.W., Patwardhan, N.A., Jovanovic, B., et al. (1991) A Population-Based Perspective of the Hospital Incidence and Case-Fatality Rates of Deep Vein Thrombosis and Pulmonary Embolism. The Worcester DVT Study. Archives of Internal Medicine, 151, 933-938.

https://doi.org/10.1001/archinte.151.5.933

[28] Morrone, D. and Morrone, V. (2018) Acute Pulmonary Embolism: Focus on the Clinical Picture. Korean Circulation Journal, 48, 365-3681.

https://doi.org/10.4070/kcj.2017.0314

[29] NATSPUTE (2006) The Clinical Features of 516 Patients with Acute Pulmonary Thromboembolism. Chinese Medical Journal, 86, 2161-2165.

[30] Altınsoy, B., Erboy, F., Tanrıverdi, H., Uygur, F., Örnek, T., Atalay, F., et al. (2016) Syncope as a Presentation of Acute Pulmonary Embolism. Therapeutics and Clinical Risk Management, 12, 1023-1028. https://doi.org/10.2147/TCRM.S105722

[31] Stein, P.D., Matta, F., Musani, M.H. and Diaczok, B. (2010) Silent Pulmonary Embolism in Patients with Deep Venous Thrombosis: A Systematic Review. The American Journal of Medicine, 123, 426-431.

https://doi.org/10.1016/j.amjmed.2009.09.037

[32] Calwin Davidsingh, S., Srinivasan, N., Balaji, P., Kalaichelvan, U. and Mullasari, A.S. (2014) Study of Clinical Profile and Management of Patients with Pulmonary Embolism-Single Center Study. Indian Heart Journal, 66, 197-202. https://doi.org/10.1016/j.ihj.2013.12.037

[33] Padley, S.P.G. (2002) Lung Scintigraphy vs. Spiral CT in the Assessment of Pulmonary Emboli. The British Journal of Radiology, 75, 5-8. https://doi.org/10.1259/bjr.75.889.750005 